\title{
Renal Expression of AQP1 in the High-fat Nutritional Obesity of Rat
}

\author{
Expresión Renal de AQP1 en la Obesidad Nutricional Alta en Grasas en Ratas
}

\author{
Jinbao Wang'; Wen Yang ${ }^{1}$; Pei Wang²; Jing Wu'; Zhisheng Wang ${ }^{1}$; Mengmeng Yang${ }^{1}$ \& Xueqin Jin ${ }^{1}$
}

WANG, J.; YANG, W.; WANG, P.; WU, J.; WANG, Z.; YANG, M. \& JIN, X. Renal expression of AQP1 in the high-fat nutritional obesity of rat. Int. J. Morphol., 37(2):406-411, 2019.

SUMMARY: AQP1 plays an essential role in maintaining body water balance. In the kidney, AQP1 is localized to the apical and basolateral membrane of epithelial cells in the proximal tubule and descending thin limb of Ansa nephroni (Henle's loop) where it reabsorbs the vast majority of filtered water. The growing epidemic of obesity and metabolic diseases particularly obesity-related kidney disease is getting more and more attention in this century. However, a full understanding of mechanisms involved to the progressive renal disease is still unclear, in particular AQPs in the kidney of obesity. In this paper, we examined the localization of AQP1 in renal cortex and medulla of ND (normal diet) and HFD (high-fat diet) at rats. In the renal cortex and medulla, immunolight microscopy revealed weak expression of AQP1 in the apical and basolateral membrane of epithelial cells at the proximal straight/convoluted tubule of HFD compared with ND, respectively. The same result was confirmed in the thick descending limb and descending thin limb of Henle's loop. In the high-fat nutritional obesity of rats, decreased AQP1 levels may not directly cause serious obesity-related kidney disease, e.g. chronic kidney disease, even end-stage renal disease. But at least, AQPs (AQP1 in this study) was one of initially conditions to the incentive of obesity-related kidney disease.

KEY WORDS: Obesity; Kidney ; AQP1; Obesity-related kidney disease

\section{INTRODUCTION}

Aquaporins (AQPs) are a family of transmembrane proteins that can act as water and other small molecules channels. AQPs play a critical role in regulating osmoregulation and homeostasis of body water. Eight AQPs are expressed in the kidney where several of them contribute to water absorption and maintenance of body water balance, e.g. AQP1, AQP2, AQP3, AQP4 and AQP7 (Kortenoeven \& Fenton, 2014).

In the kidney, AQP1 is localized to the apical and basolateral membrane of epithelial cells in the proximal tubule and descending thin limb of Henle's loop (Ansa nephroni or nephron loop) where it reabsorbs the vast majority of filtered water (Nielsen et al., 1993; Zhai et al., 2007; Kortenoeven \& Fenton). Although AQP1 trafficking or expression is not regulated by the classical vasopressin (AVP), deletion of AQP1 in mice causes severe polyuria (Katsura et al., 1995; Fenton \& Knepper, 2007). AQP1 knockout mice have a reduced urinary osmolality compared with wild-type mice (Ma et al., 1998). Consistent with the findings in AQP1 knockout mice, it was observed that humans with loss-offunction mutations in AQP1 have an impaired ability to concentrate their urine maximally when challenged by water deprivation (King et al., 2001). Furthermore, Enhancement of AQP1 function increases water transport across the peritoneal membrane, suggesting that pharmacological targeting of AQP1 would be beneficial in treatment of endstage renal disease (Morelle \& Devuyst, 2015).

The growing epidemic of obesity particularly in this century is a major factor in reducing expected life expectancy and is an added serious health and economic burden. It is related to the combination of sedentary lifestyle, also associated with a high caloric intake and a lack of exercise. To a large extent, this possible scenario would be induced via the energy intake exceeds the storage capacity of white adipose tissue, ectopic lipid accumulation in ectopic organs, thereby promoting metabolic disturbances, such as insulin resistance and alteration in the control of glucose and lipid metabolisms, contributing to hyperglycaemia, dyslipidaemia, 
hypertension, insulin resistance, glucose intolerance, and atherosclerosis (Bruce et al., 2010; Samuel \& Shulman, 2012). Moreover, central obesity is a major risk factor for diabetes and hypertension which together account for about $70 \%$ of all cases of end-stage renal disease (Collins et al., 2011). However, a full understanding of mechanisms involved to the progressive renal disease is still unclear, in particular AQPs in the kidney of obesity. Therefore, we aimed to copy the mode of high-fat nutritional obesity, and determine AQP1 expression and related functions in the obesity, thereby providing potential cross-talk between the water balance and obesity-related kidney disease.

\section{MATERIAL AND METHOD}

Sprague Dawley (SD) rats were obtained from the Laboratory Animal Center, Ningxia Medical University and Ningxia Hui Autonomous Region, and bred in the Laboratory Centre. To avoid the impact of gender on this experiment, healthy and male SD aged about 8 weeks and weighting about $240 \mathrm{~g}$ were used at the beginning of the experiment $(n=60)$. All animals were bredin-house and had free access to clean water and rat chow for the duration of the study. After 1 week of adaptive feeding, the rats were randomly divided into two groups, normal diet $(\mathrm{ND}, \mathrm{n}=30)$ and highfat diet (HFD, $n=30)$, respectively. ND was fed with normal rat chow, the fat of which accounted for $10 \%$ of the total calories. Meanwhile, HFD was fed with High-fat Diet, where the fat accounted for $66 \%$ of the total calories (Carbohydrate: $15.48 \%$; Protein: $18.08 \%$; Fat: $66.43 \%$, lard-saturated fatty acid mainly). Animals were housed in steel cages in a controlled temperature room at $23 \pm 2{ }^{\circ} \mathrm{C}$, exposed to a daily 12-hour light-dark cycle (lights on at 07:00 a.m. and off at 07:00 p.m.). Hereditary obesity (ND) and obesity-resistant (HFD) were artificially eliminated during the study. After half-year feeding, the body weight of ND and HFD were recorded. Meanwhile, kidney samples were collected and immediately fixed with $4 \%$ paraformaldehyde solution (PH7.4), and shortly afterward, blocks were cut from various parts of the kidneys for immunolight microscopy.

All experimental procedures and protocols in the study were approved by Animal Ethics Committee of the Ningxia Hui Autonomous Region, China.

For immunolight microscopy, specimens were dehydrated through a graded series of alcohol, cleared and embedded in paraffin wax, and sectioned at $5 \mathrm{~mm}$ used for immunohistochemical staining. The sections were dewaxed and rehydrated, an antigen retrieval procedure was performed to unmask antigens by treating the samples three times in a microwave oven at medium-high fire for 5 min each time in $10 \mathrm{mM}$ citrate buffer, $\mathrm{pH}$ 6. After cooling to room temperature, the sections were treated with $3 \%$ hydrogen peroxide $\left(\mathrm{H}_{2} \mathrm{O}_{2}\right)$ in distilled water for $30 \mathrm{~min}$, then washed three times with PBS for 10 min each. The sections were incubated in blocking reagent for $1 \mathrm{~h}$ and incubated overnight at $4{ }^{\circ} \mathrm{C}$ with anti-AQP1 diluted 1:200 (Boster, Wuhan, China). The primary antibody was diluted in $10 \mathrm{mM}$ PBS supplemented with $0.1 \% \mathrm{BSA}$ and $0.3 \%$ Triton X-100 [10 $\mathrm{mM}$ PBS $\left(7 \mathrm{mM} \mathrm{Na}_{2} \mathrm{HPO}_{4}, 3 \mathrm{mM} \mathrm{NaH}_{2} \mathrm{PO}_{4}, 150 \mathrm{mM} \mathrm{NaCl}\right.$, $\mathrm{pH}$ 7.4)]. Subsequently, the sections were rinsed with 10 $\mathrm{mM}$ PBS for $3 \times 10 \mathrm{~min}$ and incubated with biotinylated antirabbit IgG (ZSGB-BIO, Beijing, China, dilution: 1:200) secondary antibody for $2 \mathrm{~h}$ at room temperature. Then, the sections were rinsed with $10 \mathrm{mM}$ PBS for $3 \times 10 \mathrm{~min}$ and incubated with horseradish peroxidase streptavidin (ZSGBBIO, Beijing, China, dilution: 1:200) tertiary antibody for $2 \mathrm{~h}$ at room temperature followed by coloration with diaminobenzidine (DAB; ZSGB-BIO, Beijing, China) for 30 s to visualize positive reaction. Counterstaining was with hematoxylin staining. The sections were carried out using bright microscopy (NI-V, Nikon, Japan).

Results of body weight measurements were performed by unpaired t-test (two tailed). All data are presented as the mean \pm SEM (standard error of the mean), $* \mathrm{P}<0.05, * * \mathrm{P}<0.01$.

\section{RESULTS}

\section{Observation of body shape and weight of ND and HFD.} Body shape and data on body weight of SD rats aged 8 weeks were no significant difference between ND and HFD (ND:

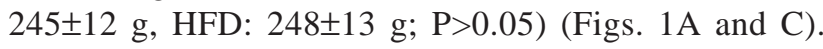
However, body shape of SD rats aged 32 weeks were observed intuitively, and were markedly difference (Fig. 1B). Data on body weight of SD rat aged 32 weeks showed a highly significant difference between ND and HFD after eliminating "obesity-resistance" (ND: 584 24 g, HFD:

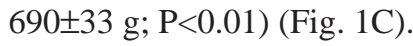

AQP1 protein examination. We examined the localization of AQP1 in renal cortex and medulla of ND (the control) and HFD at rats. Counterstaining with hematoxylin staining was used to identify negative segments (Figs. 2 and 3).

In the renal cortex, immunolight microscopy revealed strong expression of AQP1 in the apical and basolateral membrane of epithelial cells at the proximal straight / convoluted tubule of ND, respectively (Figs. 2A and C). Whereas, weak expression of AQP1 was observed in the 

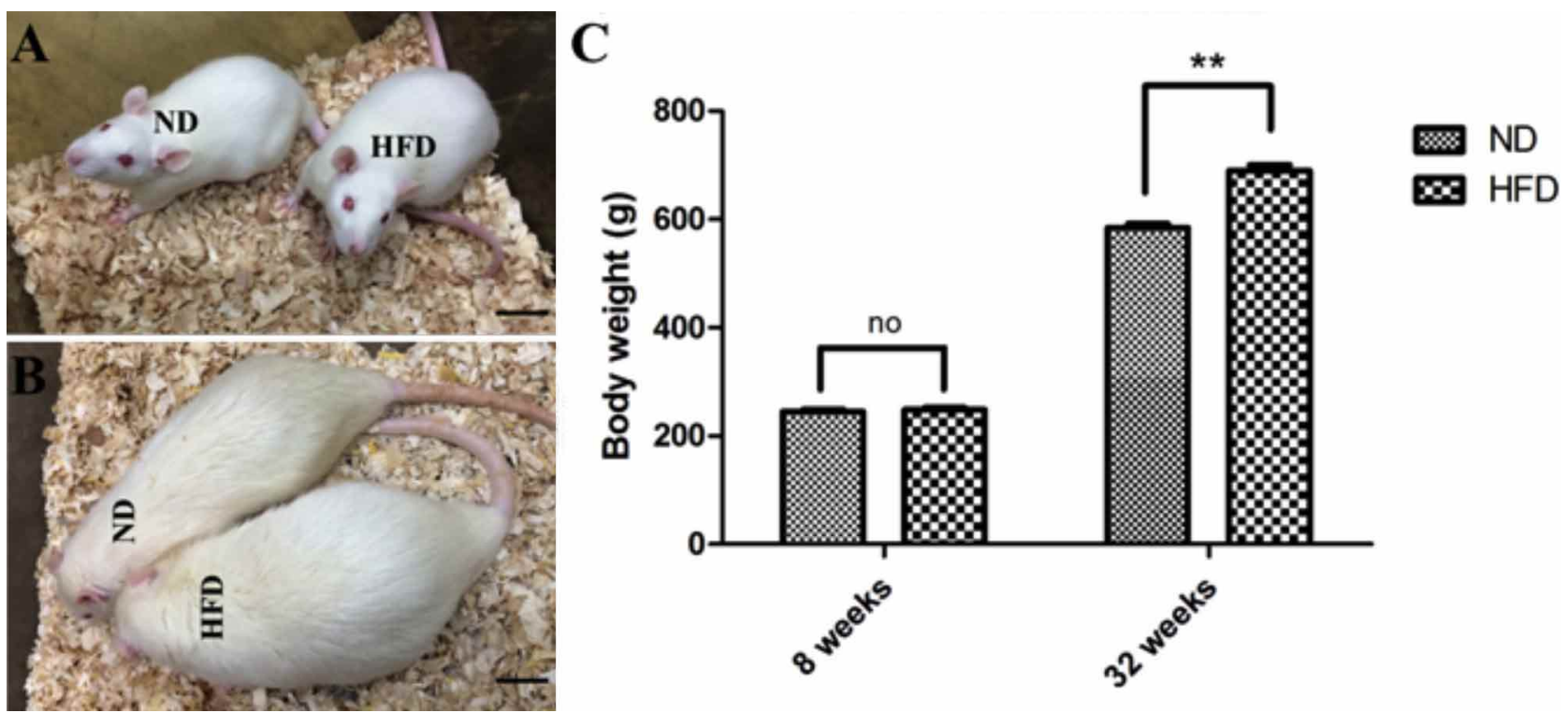

Fig. 1. Observation of body shape and weight at ND and HFD rat (ND, Normal Diet; HFD, High-fat Diet). A, SD rat aged 8 weeks; B, SD rat aged 32 weeks; C, weight difference between ND and HFD groups after eliminating "obesity resistance", **, P <0.01.
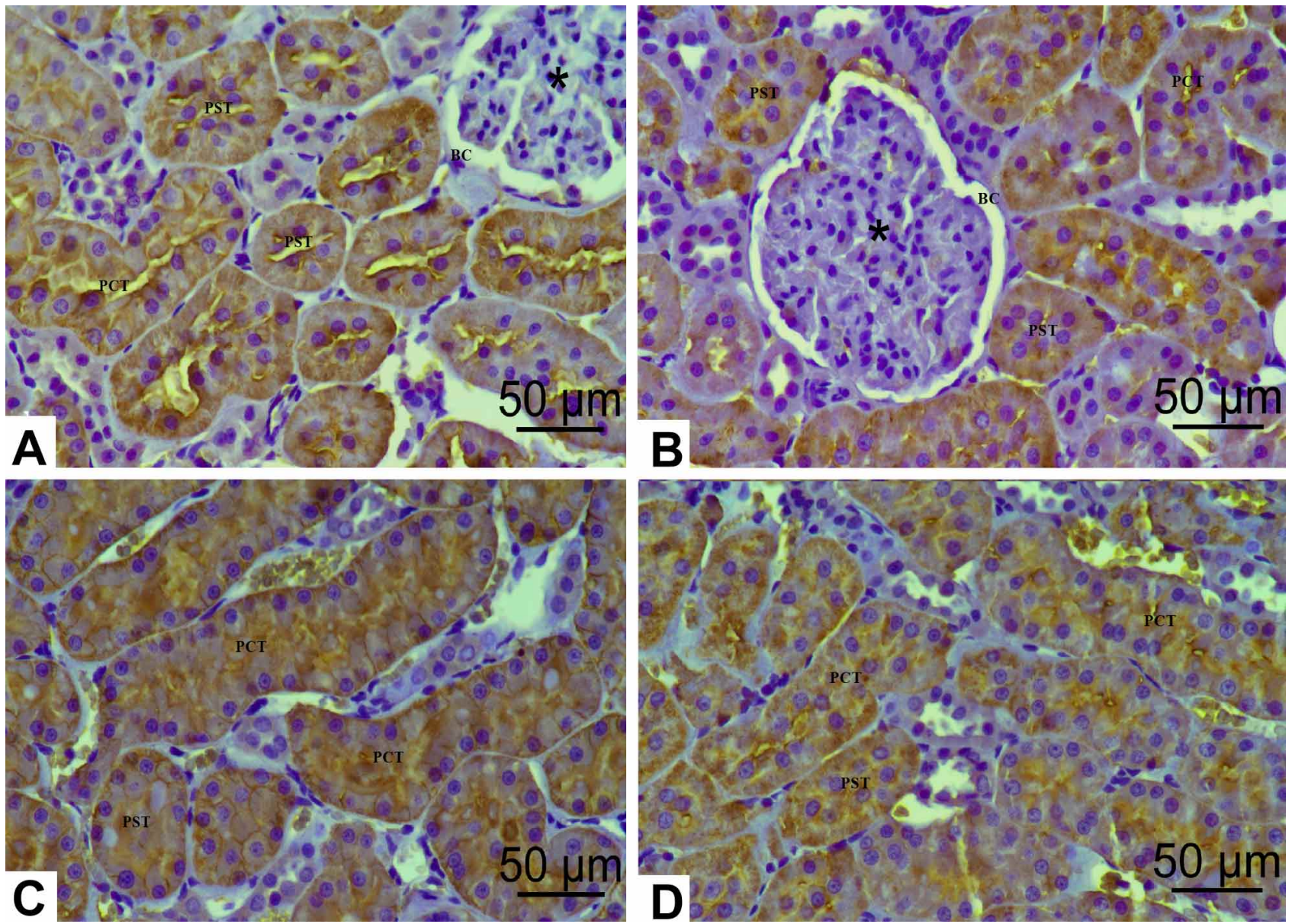

Fig. 2. Immunohistochemical examination of AQP1 protein abundance in the renal cortex in tissue section from ND (A\&C) and HFD (B\&D) rat. *, renal glomeruli; BC, Bowman's capsule; PST, proximal straight tubule; PCT, proximal convoluted tubule. 
corresponding part of HFD compared with ND, respectively (Figs. 2B and D). In the renal medulla, immunolight microscopy confirmed strong labelling of AQP1 in the thick descending limb and descending thin limb of Henle's loop of ND, respectively (Figs. 3A and C). In contrast, weak labelling of AQP1 was showed in the corresponding part of HFD compared with ND, respectively (Figs. 3B and D).
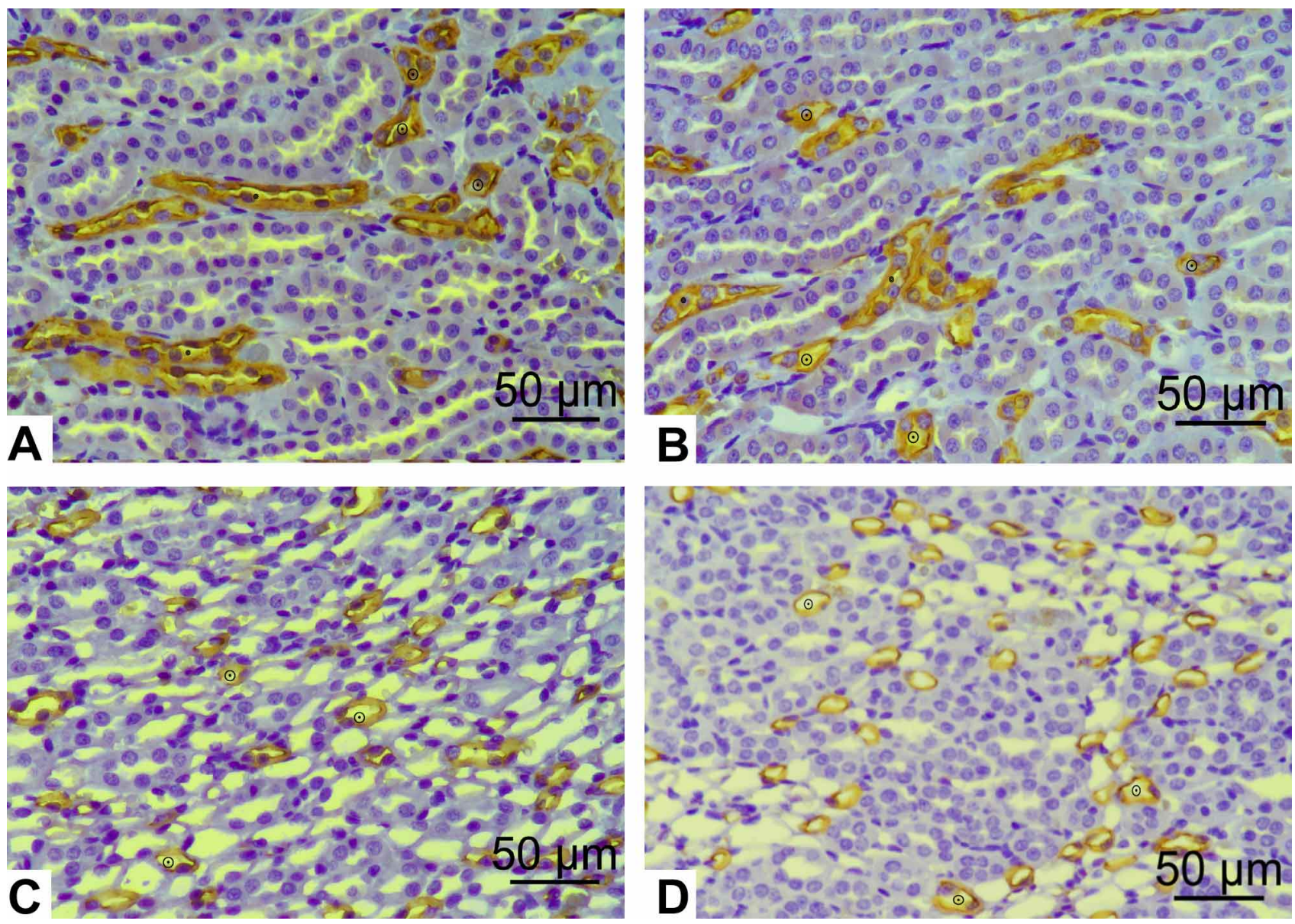

Fig. 3. Immunohistochemical examination of AQP1 protein abundance in the renal medulla in tissue section from ND (A\&C) and HFD (B \& D) rat. (), thick descending limb of Henle's loop; - , descending thin limb of Henle's loop.

\section{DISCUSSION}

Obesity-related kidney disease is associated with renal hemodynamic abnormalities, endothelial and podocyte dysfunction, glomerular basement membrane thickening and mesangial expansion, tubular atrophy, interstitial fibrosis and a progressive decrease in renal function (increased albuminuria and decreased glomerular filtration rate leading to end-stage renal disease (Marcussen et al., 1992; Taft et al., 1994; Gilbert \& Cooper, 1999; Chagnac et al., 2000). It has been suggested that pharmacological targeting of AQP1 would be beneficial in treatment of end-stage renal disease (Morelle \& Devuyst).

In kidney, AQP1 is localized in the plasma membranes of proximal tubules, descending thin limbs of Henle's loop and descending vasa recta where it appears to be the main site for water reabsorption in the proximal nephron (Nielsen et al.; Zhai et al.; Kortenoeven \& Fenton). Besides, AQP1 plays an essential role in maintaining body water balance, which is highlighted by the severe renal phenotype of AQP1 gene knockout micea (Kortenoeven \& Fenton). The major pathway for transepithelial water transport in the proximal tubule is AQP1 dependent (Schnermann et al., 1998). It has been reported that AQP1 knockout mice become severely dehydrated after water deprivation, manifesting marked serum hyperosmolality and lethargy. In addition, the rate of proximal fluid reabsorption in AQP1 knockout mice was approximately $50 \%$ reduced relative to controls (Schnermann et al.). 
Body water homeostasis is tightly controlled by regulating both water intake and urinary water excretion. In kidney, 180L of plasma is filtered by the human glomeruli each one day (Koeppen \& Stanton, 1998; Stanton \& Koeppen, 2004). But less than $1 \%$ of this volume is finally excreted in the urine. It is worth mentioning that approximately $65 \%$ of the filtered water is reabsorbed in the proximal tubule and $15 \%$ in the descending thin limb of Henle, which both are constitutive processes (Kortenoeven \& Fenton). Therefore, it is undisputed that AQP1 plays an essential role in maintaining body water balance.

Currently, obesity induced by high-fat diet is considered to be most comparable to human obesity, which can be applied to the mechanism of environmental factors (diet) on obesity, certainly including obesity-related kidney disease. Then, what was the difference of expression of AQP1 in high-fat nutritional obesity compared with normal individuals? In the present study, SD rat models of high-fat nutritional obesity was established. Compared with ND, on one hand, body shape and data on body weight of HFD rats showed a highly significant difference. On the other hand, immunolight microscopy revealed weak expression of AQP1 in the epithelial cells at the proximal straight/convoluted tubule in HFD compared with ND rats. It must be pointed out that, down-regulation of AQP1 expression in the high-fat nutritional obesity of rats, was detrimental to water reabsorption in the proximal tubule of HFD rats. Down-regulation of AQP1 produced a urinary concentrating defect in mice primarily by preventing the formation of a hypertonic medullary interstitium (Moeller et al., 2016).

Decreased aquaporin levels associated with water balance disorders, namely, down-regulation of AQP1 inevitably caused polyuria. It was similar to severe polyuria caused by deletion of AQP1 in mice (Fenton \& Knepper). Diabetes insipidus is characterized by an impaired renal water reabsorption, leading to polyuria and consequently, polydipsia (Kortenoeven \& Fenton). Therefore, there was one hypothesis that obesity would be is similar to diabetes insipidus-polyuria and polydipsia.

In medulla of kidney, immunolight microscopy confirmed weak labelling of AQP1 in the thick descending limb and descending thin limb of Henle's loop of HND compared with ND rats. It was reported that $15 \%$ of the filtered water is reabsorped in the descending thin limb of Henle's loop (Kortenoeven \& Fenton). Weak expression of AQP1 in the thick descending limb and descending thin limb of Henle's loop also produced a urinary concentrating defect, thereby resulting in an impaired renal water reabsorption.
Humans lacking functional AQP1 do not have polyuria and no obvious clinical phenotype under normal conditions. However, when challenged by water deprivation they have an impaired ability to concentrate their urine maximally (King et al.).

In the high-fat nutritional obesity of rats, decreased AQP1 levels may not directly cause serious obesity-related kidney disease, e.g. chronic kidney disease, even end-stage renal disease. But at least, AQPs (AQP1 in this study) was one of initially conditions to the incentive of obesity-related kidney disease.

In the renal cortex and medulla, compared with ND, immunolight microscopy revealed weak expression of AQP1 in the proximal tubule, in the thick descending limb and descending thin limb of Henle's loop of HFD. It was suggested that obesity led to a downregulation of AQP1. At the same time, obesity and kidney disease were inextricably linked (Declèves \& Sharma, 2015). Therefore, there was potential cross-talk between the water balance and obesityrelated kidney disease, in particular AQPs (AQP1) in the kidney of obesity. In addition, other AQPs also are expressed in the kidney where several of them contribute to water absorption and maintenance of body water balance, e.g. AQP2, AQP3, AQP4 and AQP7 (Kortenoeven \& Fenton). In a word, an more complete cross-talk between AQPs and the obesity-related kidney disease was still need to more research to be established. Further studies could focus on the molecular functions of vasopressin type-2 receptor and hormone vasopressin, combining with AQPs to investigate the obesity-related kidney diseases.

\section{ACKNOWLEDGMENTS}

We thank Lirong Zhou and Yanping Zhu (Undergraduates) for establishment the mode of high-fat nutritional obesity and assistance with sample collection in this study. This work was supported by Higher Education Scientific Research Project of Ningxia, China (NGY2017091).

WANG, J.; YANG, W.; WANG, P.; WU, J.; WANG, Z.; YANG, M. \& JIN, X. Expresión renal de AQP1 en la obesidad nutricional alta en grasas en ratas. Int. J. Morphol., 37(2):406-411, 2019.

RESUMEN: Las acuoporinas tipo 1 (AQP1) constituyen una parte esencial en el mantenimiento del equilibrio del agua en el cuerpo. En el riñón, la AQP1 se localiza en la membrana apical y basolateral de las células epiteliales, en el túbulo proximal y en el segmento descendente del Ansa nephroni o asa nefrónica (asa 
de Henle), donde reabsorbe la gran mayoría de agua filtrada. La creciente epidemia de obesidad y enfermedades metabólicas en el siglo actual, hacen que la enfermedad renal relacionada con la obesidad esté recibiendo cada vez más atención. Sin embargo, aún no existe un conocimiento definitivo de los mecanismos implicados en la enfermedad renal progresiva, en particular los relacionados a las acuoporinas renales en la obesidad. En este trabajo, examinamos la localización de AQP1 en la corteza y la médula renales de la dieta normal (DN) y dieta alta en grasa (DAG) en ratas. En la corteza y médula renales, la microscopía de luz reveló una expresión débil de AQP1 en la membrana apical y basolateral de las células epiteliales en el túbulo contorneado proximal del grupo DAG en comparación con el grupo DN, respectivamente. El mismo resultado se confirmó en la porción descendente gruesa y en la porción descendente delgada del asa nefrónica. En ratas del grupo DAG, la disminución de los niveles de AQP1 pudo no ser la causa directa de una enfermedad renal grave relacionada con obesidad, como por ejemplo, enfermedad renal crónica, o una enfermedad renal terminal. No obstante, en este estudio, la expresión renal de AQP1 constituyó una de las condiciones iniciales para inducir la enfermedad renal relacionada con obesidad.

PALABRAS CLAVE: Obesidad; Riñon AQP1; Enfermedad renal relacionada con la obesidad.

\section{REFERENCES}

Bruce, K. D. \& Hanson, M. A. The developmental origins, mechanisms, and implications of metabolic syndrome. J. Nutr., 140(3):648-52, 2010.

Chagnac, A.; Weinstein, T.; Korzets, A.; Ramadan, E.; Hirsch, J. \& Gafter, U. Glomerular hemodynamics in severe obesity. Am. J. Physiol. Renal Physiol., 278(5):F817-22, 2000.

Collins, A. J.; Foley, R. N.; Herzog, C.; Chavers, B.; Gilbertson, D.; Ishani, A.; Kasiske, B.; Liu, J.; Mau, L. W.; McBean, M. et al. US Renal Data System 2010 Annual Data Report. Am. J. Kidney Dis., 57(1 Suppl. 1):A8, 2011.

Declèves, A. E. \& Sharma, K. Obesity and kidney disease: differential effects of obesity on adipose tissue and kidney inflammation and fibrosis. Curr. Opin. Nephrol. Hypertens., 24(1):28-36, 2015.

Fenton, R. A. \& Knepper, M. A. Mouse models and the urinary concentrating mechanism in the new millennium. Physiol. Rev., 87(4):1083-12, 2007.

Gilbert, R. E. \& Cooper, M. E. The tubulointerstitium in progressive diabetic kidney disease: more than an aftermath of glomerular injury? Kidney Int., 56(5):1627-37, 1999.

Katsura, T.; Verbavatz, J. M.; Farinas, J.; Ma, T.; Ausiello, D. A.; Verkman, A. S. \& Brown, D. Constitutive and regulated membrane expression of aquaporin 1 and aquaporin 2 water channels in stably transfected LLC-PK1 epithelial cells. Proc. Natl. Acad. Sci. U. S. A., 92(16):72126, 1995.

King, L. S.; Choi, M.; Fernandez, P. C.; Cartron, J. P. \& Agre, P. Defective urinary concentrating ability due to a complete deficiency of aquaporin-1. N. Eng. J. Med., 345(3):175-9, 2001.

Koeppen, B. \& Stanton, B. A. Solute and Water Transport Along the Nephron: Tubular Function. Physiology. St. Louis, Mosby,1998. pp.710-3.

Kortenoeven, M. L. \& Fenton, R. A. Renal aquaporins and water balance disorders. Biochim. Biophys. Acta, 1840(5):1533-49, 2014.

Ma, T.; Yang, B.; Gillespie, A.; Carlson, E. J.; Epstein, C. J. \& Verkman, A.
S. Severely impaired urinary concentrating ability in transgenic mice lacking aquaporin-1 water channels. J. Biol. Chem., 273(8):4296-9, 1998.

Marcussen, N. Atubular glomeruli and the structural basis for chronic renal failure. Lab. Invest., 66(3):265-84, 1992.

Moeller, H. B.; Fuglsang, C. H. \& Fenton, R. A. Renal aquaporins and water balance disorders. Best Pract. Res. Clin. Endocrinol. Metab., 30(2):277-88, 2016.

Morelle, J. \& Devuyst, O. Water and solute transport across the peritoneal membrane. Curr. Opin. Nephrol. Hypertens., 24(5):434-43, 2015.

Nielsen, S.; Smith, B. L.; Christensen, E. I.; Knepper, M. A. \& Agre, P. CHIP28 water channels are localized in constitutively water-permeable segments of the nephron. J. Cell Biol., 120(2):371-83, 1993.

Samuel, V. T. \& Shulman, G. I. Mechanisms for insulin resistance: common threads and missing links. Cell, 148(5):852-71, 2012.

Schnermann, J.; Chou, C. L.; Ma, T.; Traynor, T.; Knepper, M. A. \& Verkman, A. S. Defective proximal tubular fluid reabsorption in transgenic aquaporin-1 null mice. Proc. Natl. Acad. Sci. U. S. A., 95(16):9660-4, 1998.

Stanton, B. A. \& Koeppen, B. M. Solute and Water Transport along the Nephron: Tubular Function. Physiology. St. Louis, Elsevier Mosby, 2004. pp.643-58.

Taft, J. L.; Nolan, C. J.; Yeung, S. P.; Hewitson, T. D. \& Martin, F. I. Clinical and histological correlations of decline in renal function in diabetic patients with proteinuria. Diabetes, 43(8):1046-51, 1994.

Zhai, X. Y.; Fenton, R. A.; Andreasen, A.; Thomsen, J. S. \& Christensen, E. I. Aquaporin-1 is not expressed in descending thin limbs of short-loop nephrons. J. Am. Soc. Nephrol., 18(11):2937-44, 2007.
Corresponding author:

Jinbao Wang

Laboratory Animal Center

Ningxia Medical University

Ningxia Hui Autonomous Region

Yinchuan

750004 Ningxia

CHINA

Email: wangjinbao123asd@126.com

Received: 04-09-2018

Accepted: 12-12-2018 